\title{
Paisaje y paisajes en el País Vasco: síntesis diacrónica de su configuración y consideración normativa
}

\section{Landscape and landscapes in the Basque Country: diachronic synthesis of its configuration and normative consideration}

\author{
Orbange Ormaetxea Arenaza ${ }^{1}$, Ana Sáenz de Olazagoitia Blanco ${ }^{2}$
}

\begin{abstract}
RESUMEN
Este trabajo recoge de forma sucinta aquellas características del espacio físico que condicionan el carácter de los paisajes del País Vasco y realiza un recorrido diacrónico y resumido de la adaptación antrópica a esos ámbitos a través de la actividad y la ocupación del suelo. En segundo lugar, el análisis pormenorizado de los datos de ocupación de suelo de las últimas décadas, además de destacar aspectos metodológicos y de interpretación de resultados de las fuentes de datos consultadas, permite determinar a escala provincial cuáles han sido los cambios de ocupación y por tanto paisajísticos desde la década de 1970. Por último, se realiza un recorrido de la consideración del paisaje desde el apartado normativo como patrimonio de carácter universal, valor de calidad con la designación de Paisajes Singulares y Sobresalientes, valor de conservación y de protección, componente visual y elemento percibido por la población hasta culminar en el actual marco del Convenio Europeo del Paisaje.
\end{abstract}

Palabras clave: Factores de configuración del paisaje; datos de ocupación del suelo; consideración normativa; Comunidad Autónoma del País Vasco.

1 Universidad del País Vasco UPV-EHU orbange.ormaetxea@ehu.es ORCID iD: http://orcid. org/0000-0001-8573-2806

2 Universidad del País Vasco UPV-EHU ana_saenzdeolazagoitia@ehu.eus ORCID iD: http:// orcid.org/0000-0003-1912-0259

Copyright: (0) 2018 CSIC. Este es un artículo de acceso abierto distribuido bajo los términos de la licencia de uso y distribución Creative Commons Reconocimiento 4.0 Internacional (CC BY 4.0). 


\section{Abstract}

This work summarizes succinctly those characteristics of the physical space that determine the character of the landscapes of the Basque Country. It also performs a diachronic and summarized account of the anthropic adaptation to these areas through activity and land use. Furthermore, the detailed analysis of the land cover data in recent decades, while highlighting the methodological features and the interpretation of the results from the sources of consulted data, aids to determine at a provincial level the changes of occupation, and therefore landscape since the 1970s. Lastly, we carried out an analysis from the normative approach considering the landscape as a universal heritage, with quality value with designation of Singular and Outstanding Landscapes, value of conservation and protection, visual asset as well as elements perceived by the citizenship and therefore to be considered in the new framework of the European Landscape Convention.

KEY WORDS: Factors of landscape configuration; land cover data; normative consideration; Autonomous Community of the Basque Country.

Cómo citar este artículo/Citation: Ormaetxea Arenaza, Orbange, Sáenz de Olazagoitia Blanco, Ana (2018): "Paisaje y paisajes en el País Vasco: síntesis diacrónica de su configuración y consideración normativa”, Estudios Geográficos, LXXIX/284, pp. 85-113

\section{INTRODUCCIÓN}

El paisaje en su dimensión visual tiene un carácter determinado por sus factores genéticos, naturales y/o antrópicos y siendo estos diversos también lo es el paisaje. Los paisajes son así las escenas de sistemas ambientales y territoriales (De Groot, 2006: 177-178) que tienen, como recoge el autor, las funciones de regulación, hábitat, producción, información y transporte. El espacio físico en el que se desarrollan es fuente de recursos, soporte y receptor de los efluentes de la actividad. Y por tanto dinámico, cambiante y con un margen de sostenibilidad en tanto, ya ha sido señalado (Gómez Orea, 2002: 192), no se supere la tasa de renovación de esos recursos, de asimilación de efluentes o su capacidad de acogida. En las últimas décadas el ritmo y la magnitud de esos cambios está siendo tal que, aún relativizando la importancia de la superficie urbanizada como hacen algunos autores (Lambin et al., 2001: 261), se constatan ejemplos de pérdida de diversidad y de aumento de la homogeneidad (Tarroja, 2008: 240) e incluso de creación de paisajes con condiciones ecológicas diferentes a las del contexto natural (Antrop, 2006: 28). Los recursos y efluentes son transferidos de y a otros sistemas y la tecnología permite modificar las limitaciones de la capacidad 
de acogida convirtiendo al paisaje en principal expresión de este contexto de acción.

Por otra parte, en la adaptación a ese espacio de las personas y las sociedades y en esa acción y estructuración antrópica a lo largo del tiempo, el paisaje ha ido adquiriendo múltiples dimensiones: patrimonio (UNESCO, 1962), bien común (Makarow et al., 2010: 1-16) y valor psicofísico (Kaplan, 1987: 3-32), económico (Tagliaferro et al., 2013: 26-36) o ecológico (Constanza et al., 1997: 253-260), entre otros. De esta manera los paisajes se pueden caracterizar y tipificar no sólo atendiendo al resultado de unos factores, a la función sistémica que expresan, sino también como valor (Cruz y Español, 2009: 119-131). Un valor que dependerá de sus características intrínsecas como también de su percepción por quien lo hace o lo vive a través de una relación sensible y en la que intervienen las características individuales como colectivas de quien lo percibe (Zube et al., 1982: 1-33; Gómez y Riesco, 2010: 80; Mata et al., 2009: 259-279). De ahí que el paisaje de un territorio no sólo exprese condición ambiental y acción antrópica sino también sentimiento por él.

El marco actual del Convenio Europeo (CEP, 2000) da una nueva dimensión al paisaje al entender éste, además de como producto ambiental, territorial, social y valor; como proyecto de sociedad, con carácter jurídico, normativo e instrumental, no sólo de los planificadores, sino también del conjunto de la población a través de la participación en la formulación de objetivos de calidad.

En este contexto, la Comunidad Autónoma del País Vasco (CAPV), como todo territorio, ha tenido un recorrido de construcción y evolución de paisajes a través del uso y la actividad y también de consideración normativa del paisaje y su valor hasta su adhesión al CEP, y que este trabajo tiene por objetivo presentar. Para ello, se ocupa en primer lugar de identificar y describir los principales condicionantes ambientales y culturales del carácter de los paisajes de este territorio. Como segundo objetivo se plantea el análisis cuantitativo de los datos de ocupación del suelo de la Comunidad Autónoma desde el último cuarto de siglo, con el fin de recoger a escala regional las transformaciones de uso y por tanto paisajísticas que se han producido desde la década de los 70, momento de la realización de la primera cartografía forestal. Y como tercer objetivo, pretende hacer una síntesis del recorrido institucional en la consideración del paisaje y en el reconocimiento del valor de los paisajes de la CAPV hasta la actualidad cuando, como requiere el CEP, ya hay un marco normativo e instrumentos específicos en paisaje. 
ANTECEDENTES, Fuentes y METOdOlogía DE TRABAJO

La identificación de los paisajes de la CAPV, así como la utilización de datos de superficies de uso para la caracterización de cada uno de los territorios que la componen, tienen como antecedentes diferentes obras de carácter referencial desde finales del siglo pasado (AAVV, 1980; AAVV, 1979; Aguirre, 1979; Meaza y Ruíz, 1994-1998; Ainz et al., 1999; Ruíz y Galdos, 2008; HAZI, 2013). Y también son diversos los autores que han analizado las políticas del paisaje en el Estado (Frolova et al., 2004; Frolova, 2009; Hervás, 2009; Serrano, 2007; Mulero, 2013; Zubelzu y Allende, 2015) así como en la Comunidad Autónoma (Ormaetxea, 2002; Aranburu et al., 2006; Askasibar, 2009).

Las fuentes para la consecución de este trabajo han sido la información cartográfica como documental. Se ha dispuesto de la cartografía temática accesible en la Infraestructura de Datos Espaciales de Euskadi (IDE de Euskadi) así como de diversas cartografías forestales que también incluyen los datos sobre otros tipos de usos de suelo: el Inventario Forestal Nacional IFN1 (en el País Vasco realizado en 1972), el Inventario Forestal del País Vasco (1986), el Inventario Forestal Nacional IFN2 (1996), el Inventario Forestal Nacional IFN3 (2005) y el Inventario Forestal Nacional IFN4 (2011) (Sáenz y Cantero, 2001; HAZI, 2013). Están también disponibles los datos recogidos en el Sistema de Información de Ocupación del Suelo de España SIOSE (2005), pero en este análisis no se han incluido por su coincidencia en el tiempo con el IFN3. Se ha contado también con los datos aportados por CORINE Land Cover de 1990 (CLC1990), 2000 (CLC2000) y 2006 (CLC2006), base de datos numérica y geográfica a escala 1:100.000.

Por su parte las fuentes de información documental han sido de carácter principalmente descriptivo para la caracterización ambiental (Barnolas y Pujalte, 2004: 233-241; Loidi et al., 2011) e histórico para la síntesis de acción cultural (Bilbao et al., 1984; Fernández de Pinedo, 1974; García de Cortazar y Lorenzo, 2000; Urzainki, 2007; Uriarte, 2008; Michel y Gil, 2013). Además en la identificación actual se han utilizado fuentes de datos estadísticos (EUSTAT, INE).

Por último y para el tercer objetivo, la consideración del paisaje en la CAPV, se ha utilizado información referida a las políticas de conservación y protección como de ordenación del territorio implementadas en esta comunidad y que tienen relación con el paisaje, así como aquellos documentos que recogen inventarios o catálogos sobre el valor ambiental y estudios sobre la valoración de sus paisajes. 
La metodología de trabajo ha seguido una perspectiva geográfica clásica (Rodríguez, 1979: 23-42) de análisis y tratamiento de datos espaciales y recopilación bibliográfica que permiten elaborar una interpretación sintética y diacrónica de procesos que intervienen en el paisaje y que están recogidos en el concepto del CEP: la acción natural y humana y sus interrelaciones, y la percepción de la población.

SíNTESIS DE CONDICIONANTES AMBIENTALES Y CULTURALES EN LA CONFIGURACIÓN DE LOS PAISAJES DE LA CAPV

\section{Condicionantes ambientales}

En sus $7.235 \mathrm{~km}^{2}$ de superficie el paisaje de la CAPV es valle y monte, llanura y sierra, es litoral y su origen es mayoritariamente marino. La historia de su soporte geológico, excepto en el Macizo paleozoico de Peñas de Aia (Gipuzkoa) y en la Depresión del Ebro (Rioja Alavesa), comienza en un mar epicontinental de edad triásica que se fue abriendo y hundiendo hasta principios del Eoceno. Por ello, la unidad geológica que sustenta este territorio se denomina Cuenca Vasco-Cantábrica (Barnolas y Pujalte, 2004: 233-241). Caracterizada por la gran potencia de su sucesión mesozoica esta cuenca marina también fue diversa en accidentes tectónicos y ambientes deposicionales y por ello se distinguen un Arco Vasco al norte y un Surco NavarroCántabro al sur. El primero está determinado, entre otros, por procesos que hoy día tienen un reflejo paisajístico: la existencia de magmatismo cretácico y potentes sucesiones del Jurásico, Cretácico y Paleógeno, mayoritariamente de condiciones marinas abiertas y cuyos testigos actuales son, ya en estructuras derivadas e incluso invertidas por la erosión, las cimas calizas y karstificadas de los Montes Vascos y las importantes acumulaciones turbidíticas en el surco flysch que caracterizan buena parte de los acantilados vascos o la alineación montuosa del sinclinorio vizcaíno (figura 1). Por su parte el Surco NavarroCántabro, que ocupa el sector central y septentrional de Araba/Álava, si bien marino y con depósitos de margas y calcarenitas, no alcanzó condiciones profundas. Durante la orogenia alpina fue levantado y deformado en sucesivos pliegues y su frente sur transportado, cabalgando sobre la Depresión del Ebro. Estos esfuerzos determinaron también la existencia de cuencas endorreicas de carácter aluvio-lacustre con depósitos de areniscas y conglomerados que hoy componen los paisajes rojizos de las suaves charnela y flancos del sinclinal de Miranda-Treviño (ITGE, 1989). 
FIGURA 1

MAPA GEOLÓGICO ESQUEMÁTICO DE LA CAPV

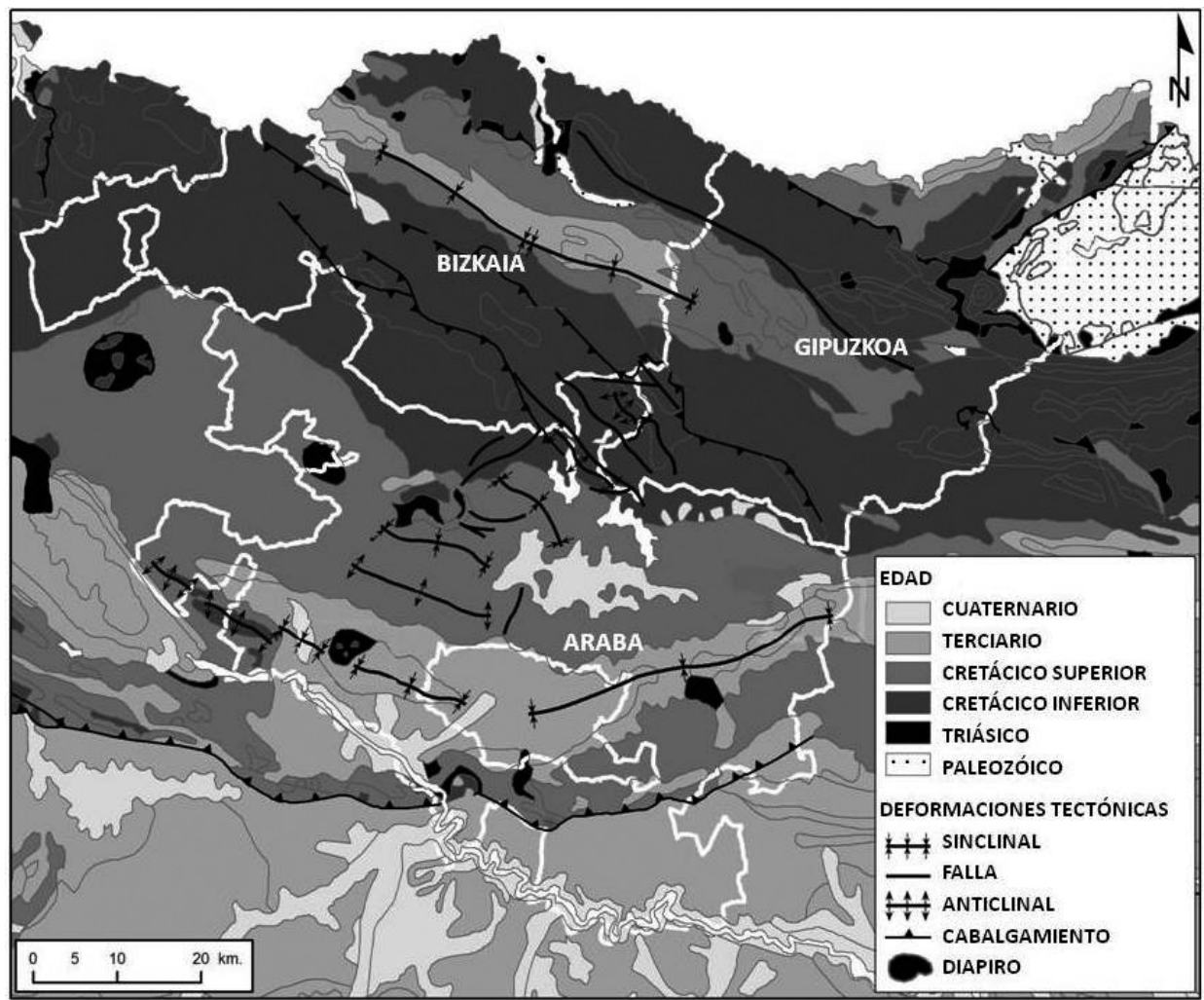

Fuente: ITGE, 1989.

Relieves plegados y fallados que en numerosos puntos son perforados por materiales de menor densidad y mayor ductilidad hasta llegar a extruir o quedar aflorantes por desmantelamiento erosivo. En el País Vasco hay dos tipos de estructuras perforantes, el Macizo de Peñas de Aia en el extremo oriental de Gipuzkoa y único ejemplo de stock granítico, y las extrusiones diapíricas halocinéticas y tectónicas repartidas en el conjunto del ámbito. En el Arco Vasco los diapiros, relacionados con factores de emplazamiento y presencia de fallas, determinan paisajes característicos que tienen como exponente la Reserva de la Biosfera de Urdaibai. Los diapiros del Surco Navarro-Cántabro tienen origen halotectónico (Montoria y Ocio en Araba/Álava) como halocinético (Murgía, 
Orduña, Salinas de Añana, Maeztu, Peñacerrada y Salinillas de Buradón en Araba/Álava) y también dibujan paisajes subcirculares singulares (Serrano y Martínez del Olmo, 2004: 334-338).

Y singular es asimismo el paisaje de la Depresión del Ebro respecto del resto del territorio de la Comunidad Autónoma por su contraste estructural, litológico y morfológico. Aquí, a los pies del farallón calcáreo de la Sierra de Toloño-Cantabria-Codés, los depósitos terciarios y cuaternarios han sido erosionados aislando husos conglomeráticos, cerros testigo, glacis y terrazas colgadas; incidiendo barrancos y dibujando bad-lands; configurando, en definitiva, un paisaje de carácter diferente.

Sobre ese soporte litológico se ha desarrollado, a expensas de un aporte de precipitación que varía desde los más de $2.200 \mathrm{~mm}$ anuales del extremo nororiental hasta los $400 \mathrm{~mm}$ del límite meridional, un sistema fluvial distribuido en dos vertientes, una cantábrica $\left(4.507 \mathrm{~km}^{2}\right)$ y otra mediterránea $\left(2.728 \mathrm{~km}^{2}\right)$. En la primera, la red fluvial en un $22 \%$ de su longitud, atraviesa pendientes superiores al 30\% y casi la mitad del territorio (48\%) tiene esos valores de pendiente. Mientras, en la segunda, el 60\% del recorrido de los cauces discurre a través de tierras con pendiente inferior al 10\% y sólo el $13,3 \%$ de esta vertiente tiene pendientes superiores al 30\%. Vertientes y valles por tanto de fisiografía distinta y así también su paisaje, «doméstico y pequeño» (Unamuno, 1952: 16) el primero, «escalón entre la lozana fragosidad del campo vasco y la austera sequedad del castellano» (Baroja, 1953: 16) el segundo.

Por su parte, condicionantes litológico-edáficos, agua y temperatura influyen en una biota de bosque diverso (el bosque natural ocupa 204.964 ha, el 26\% de la CAPV). El piso colino de la vertiente cantábrica está caracterizado por la presencia de masas de robledal (Quercus robur), bosques mixtos de frondosas y encinar en los suelos calizos (Quercus ilex subsp. ilex); así como pequeñas manchas de marojal (Quercus pyrenaica) en los suelos más ácidos y robledales de roble albar (Quercus petraea) y de quejigales (Quercus faginea) en el extremo occidental. En torno a los $600 \mathrm{~m}$ se extiende el haya (Fagus sylvatica) atravesando la barrera orográfica de la divisoria de aguas y adentrándose en las sierras alavesas. En ellas y por debajo de aquella, en un ámbito cada vez más continentalizado, se desarrollan ampliamente los rebollares o marojales (en el Parque Natural de Izki se encuentra el bosque más extenso de esta especie en Europa con 3.500 ha) y adquieren su máxima expresión también el quejigo encinariego (Quercus faginea) y los carrascales (Quercus ilex subs. rotundifolia) (Loidi et al., 2011). 


\section{Condicionantes culturales}

Sobre esos paisajes de condición ambiental la dimensión humana se ha integrado construyendo la obra, las escenas de un sistema complejo en el que los diversos mecanismos han dirigido las actividades humanas condicionando el dinamismo de la naturaleza (Farina, 2011: 15) y de ahí la diversidad de paisajes culturales. De esa adaptación histórica al medio, «Nuestro País v.g. apenas tiene otro sobrante que el fierro [...] No podemos, comerle, beberle ni vestirnos con él; con que ó lo hemos de sacar á fuera para traher en cambio lo que nos falta, ó hemos de morir de hambre, de frío y de miseria» (RSBAP, 1768: 181), han quedado escenas y testigos de paisaje: los santuarios paleolíticos de la comunidades de caza y pesca, las estaciones megalíticas de culturas agrícolas y pastoriles, las explotaciones mineras romanas, ferrerías y moliendas, las ciudades y villas medievales, los puertos de mar y monte o toda la dispersión de núcleos de la tierra llana y las casas torre banderizas bajomedievales, los vestigios de los astilleros de la Edad Moderna o de las fábricas de acero de la Contemporánea (García de Cortazar y Lorenzo, 2000). Industrias extractivas, de siderurgia y metalurgia, naval, papel y textil; y más recientemente de mueble, electrodoméstico, máquina-herramienta, automoción, química o petroquímica hasta los parques tecnológicos de las últimas décadas han ido configurando un paisaje industrial productivo también diverso en el tiempo y el espacio. Esa manera de organizar específica en función de la actividad (Cruz y Español, 2007: 128) y su evolución en el tiempo tienen como resultado toda una tipología de paisajes industriales (desde los considerados patrimoniales y reconvertidos en recurso cultural y turístico, hasta los más innovadores o los degradados por el abandono) que dan carácter al territorio. En la actualidad, si bien la superficie ocupada por las actividades económicas no llega al 2\% de cada uno de los Territorios Históricos (Araba/Álava 0,91\%, Bizkaia 1,6\%, Gipuzkoa $1,36 \%$, EUSTAT, 2015) su impronta visual en los núcleos y valles en los que se asienta y en las infraestructuras de comunicación que bordea es nítida.

Como también lo es el paisaje de la residencia, de la habitación. Bizkaia a pesar de ser el territorio más pequeño (198.000 ha) tiene la mayor superficie de suelo residencial consolidado (5.689 ha concentradas mayoritariamente en el área metropolitana de Bilbao), seguida de Araba/Álava (4.287 ha en 303.700 ha de territorio y aglutinadas principalmente en Vitoria-Gasteiz) y Gipuzkoa (4.055 ha de suelo residencial con carácter más disperso, repartido en 221.700 ha de superficie total). Industrial y residencial, ambos tipos de uso de suelo y sistemas, para su comunicación y el transporte, necesitan de una infraestructura que, de nuevo en el caso de Bizkaia, destaca por su mayor dimensión espacial 
(4.306 ha) respecto de Araba/Álava (2.928 ha) y Gipuzkoa (2.463 ha). Y que en todos los casos es visible en el territorio ya que, de los $13.690 \mathrm{~km}$ que la componen, un $27 \%$ transcurre por laderas de pendiente mayor al $30 \%$.

En contraste con esos paisajes artificiales y resultado de una simbiosis natural y cultural se encuentra la matriz del paisaje de esta Comunidad Autónoma: el paisaje forestal, con árboles que fueron «bravos» para industrias navales y edificios, «jaros» y «trasmochaderos» para leña y carbón. En realidad, buena parte de los bosques descritos en el apartado ambiental fueron durante siglos sistemas controlados de viveros y plantaciones cuya situación y estado ha sido resultado de vaivenes socioeconómicos y políticos. Principales hitos en la evolución y transformación del paisaje forestal fueron la demanda de carbón vegetal para las ferrerías, las grandes talas realizadas con destino a la Real Armada; el endeudamiento de los Ayuntamientos en las sucesivas guerras del siglo XIX que supuso, primero el talado de los árboles (Michel y Gil, 2013: 262) y posteriormente la enajenación de propiedades comunales; la llegada de las plagas conocidas como tinta del castaño y oidium del roble o la repoblación de esos montes esquilmados con especies exóticas de rápido crecimiento del siglo pasado (Uriarte, 2008: 239-268). Esa repoblación ocupa en la actualidad el 28,9\% (coníferas y eucaliptus, $207.196 \mathrm{ha}$ ) del espacio vasco. Un paisaje que, bien por abandono de usos agrarios y ganaderos (Ruíz y Galdos, 2013a: 379-398), bien por políticas que garantizan la diversidad y permanencia de los montes arbolados (Ley 16/1994 de Conservación de la Naturaleza; Plan Forestal Vasco, 1994-2030) ha visto aumentar su superficie (Confederación de Forestalistas del País Vasco, 2013: 3033).

Por su parte en la cultura de este territorio y por tanto en su paisaje también están el «agro» y la ganadería. Las condiciones ambientales han determinado secularmente tres ámbitos: uno septentrional-húmedo; otro central, de condición más seca y de mayor rigor térmico; y por último, otro meridionalmediterráneo (Bilbao et al., 1984: 97). En ellos, las especies, su rotación y la roturación de tierras han sido resultado de un proceso que incluye ambiente pero también sociedad (figura 2).

En el ámbito septentrional y gestionado por el caserío, en las tierras de labor se cultivaron árboles frutales — manzano, vid y castaño— y cereales con carácter deficitario, «El Señorío de Bizkaia y provincia de Gipúzcoa son tierras de poco pan y vino. En algunas partes comen pan de mijo, que llaman borona; beben vino de manzanas que llaman sidra; por la mayor parte se proveen de pan y vino de otras partes, que traen por mar y por tierra» (De Medina, 1548, citado en: Pastor y Salaverri, 2012: 141) hasta la introducción del maíz a finales del siglo XVI que supuso además, un cambio en la localización de la actividad 


\section{FigURA 2}

IMÁGENES DE LA DIVERSIDAD DE PAISAJES EN LA CAPV COMO RESULTADO DE LA ADAPTACIÓN ANTRÓPICA AL MEDIO.

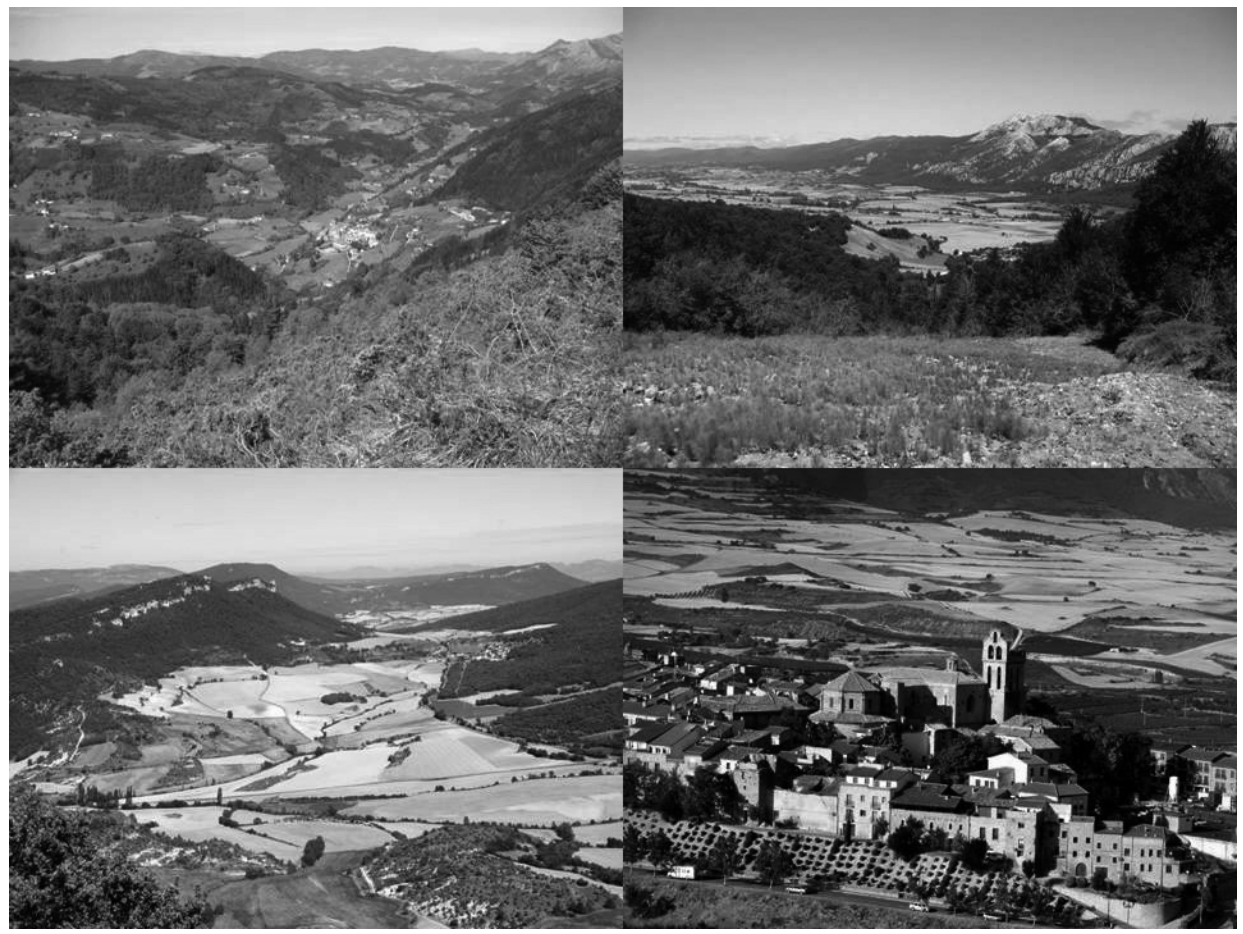

Comarcas de Tolosaldea, Llanada Alavesa, Valles Alaveses y Rioja Alavesa.

agrícola con su traslado al fondo de los valles (Fernández de Pinedo, 1974: 27). Junto al «solo» (predio agrícola) la ganadería fue también en ese tiempo actividad y configuradora de paisajes, como es el caso de los «seles», espacios de propiedad particular o concejil rodeados del monte y el bosque comunal, de morfología circular y de diferente tamaño, de los que aún quedan algunos testigos (IDE de Euskadi, 2015) y que en origen eran los lugares donde sesteaba el ganado (Díaz de Durana, 1998: 19-38).

Para el siglo XIX las siembras de cereal (excepto el maíz) y el lino, como las pomaradas y los castaños van retrocediendo, y en cambio se van extendiendo la patata y los prados artificiales. A mediados del siglo pasado esta diversidad de usos desaparece a favor de una especialización productiva en una economía de mercado en la que se opta por la ganadería, primero de dedicación láctea 
y posteriormente cárnica (Ruíz y Galdos, 2008: 289-290). Ganadería en todo caso con necesidad de praderas de corta y diente, y configuradoras del paisaje de campiña característico de esta vertiente cantábrica. Ya en este siglo, junto a la campiña y salpicándola, se encuentran los cultivos bajo plástico ligados a productos de calidad (Label Vasco de Calidad Alimentaria) y mercados comarcales (1.177 ha), laderas con espalderas de vid para «txakoli» con Denominación de Origen (1.014 ha), pomaradas en los valles guipuzcoanos que han mantenido la tradición sidrera y otros frutales con un reparto diseminado (1.999 ha; INE, Censo Agrario 2009).

En la actualidad, campiña y cultivos hortofrutícolas dibujan junto a las masas forestales y los nuevos modos de urbanización dispersa el actual mosaico cantábrico no urbano. Un paisaje en el que la Superficie Agraria Útil SAU ocupa un 20,1\% en Gipuzkoa (43.695 ha) y un 22,1\% en Bizkaia (44.598 ha), pero en el que los pastos permanentes ocupan el 90,6 y 90,8\% respectivamente de ese SAU. En ellos, el ganado bovino y ovino es también elemento de paisaje. Gipuzkoa censa en 2009 una cabaña ganadera de bovino de 49.546 cabezas y 142.451 de ovejas (Denominación de Origen del queso Idiazabal); Bizkaia, 49.288 de bovino y 64.990 de ovino.

En este espacio agroganadero hay otro proceso territorial y hecho paisajístico desde finales del siglo pasado y es la nueva vocación exclusivamente residencial para este suelo. Así, respecto a la ocupación de este espacio por la casa que no es caserío, basta decir que si bien el número de explotaciones agrarias del último Censo Agrario era de 7.050 para Bizkaia y 5.790 para Gipuzkoa, el número de viviendas en suelo no urbanizable era de 29.201 y 15.947 respectivamente y el número de viviendas familiares con una única vivienda en el edificio aumentó en la década 1991-2011 en 1,28 para Bizkaia y 1,33 para Gipuzkoa (EUSTAT, 2015).

En el ámbito central y gestionado desde las aldeas, el cultivo de cereal ha sido durante siglos principal rasgo paisajístico del «ager». El trigo fue cultivo mayoritario seguido por la cebada y otras leguminosas como el haba o la lenteja que se utilizaban para alimento del ganado. En el pasado siglo gracias al proyecto de la Estación de Mejora de Cultivos de la Patata de selección de semillas, este cultivo se convirtió, tras los cereales, en principal producción de varias de las comarcas de Araba/Álava (Valles Alaveses, Montaña Alavesa y Llanada Alavesa, 7.559 ha, Censo Agrario 1989). Para ese siglo también el cultivo de la remolacha azucarera fue protagonista de la actividad agrícola y del paisaje (3.110 ha; Censo Agrario 1999). Actualmente, ese territorio, con una estructura modificada por la concentración parcelaria y una amplia reducción de la superficie dedicada a patata (1.929 ha, 2009) y remolacha azucarera (2.045 ha, 2009) sigue manteniendo su vocación cerealista (ahora con un 
barbecho subvencionado - 3.326 ha-). Así, en el Censo Agrario de 2009, con una SAU de 102.102 ha (33,6\% de Álava), corresponde a suelos labrados el $69,3 \%$, (70.760 ha, de las cuales 17.191 ha se dedicaban a trigo y 15.087 ha a cebada). En estos paisajes caben mencionar como hitos paisajísticos recientes las construcciones para guardar cosechadoras y aperos, y las lagunas artificiales que, de forma dispersa en cada valle, abastecen la superficie regada (6.376 ha).

Los espacios hasta ahora descritos, cantábrico y central, comparten un tipo de paisaje y una actividad secular en cerros y cimas, los pastos «larreak». Éstos eran actividad del común hasta el siglo XIX con la desamortización eclesiástica, estatal y civil y la apertura del Registro de la Propiedad en 1898, contexto en el que el bien comunal pasó a ser propiedad privada o pública (Bikandi, 1982: 62-74). En la actualidad el monte privado supone el 53,8\% de la CAPV y el público el 46\%. Este último a su vez puede ser «de dominio público» o demanial y «patrimonial». En el primero quedaron inscritos aquellos bienes y su aprovechamiento en común (entre los que estaba el pasto) en los montes catalogados hoy día como de Utilidad Pública. En la actualidad esta titularidad supone el 28,4\% —205.986,13 ha - de la superficie del País Vasco, aunque más del 65\% de la misma se encuentra en territorio alavés. De carácter público pero «patrimonial», son las $5.457,7$ ha de las respectivas Diputaciones Forales y los montes públicos de entidades locales (de "propios") que ocupan 13.344,7 ha, además de una pequeña extensión (2.259 ha) propiedad del Estado (MAGRAMA, 2013).

En ese monte, la cultura del pastoreo extensivo ha dejado improntas megalíticas que datan del Neolítico, espacios abiertos de herbazales entre árboles y una estructura territorial que, aunque en retroceso, aún sigue vigente en escena, la majada «saroia». Un espacio en altura donde el ganado sestea y donde se encuentra la casa del pastor «txabola» y otras edificaciones más modestas para albergar animales y enseres, acompañado todo ello de un pequeño huerto y el cerrado para los animales (Urzainki, 2007). Son los paisajes de la oveja autóctona «latxa», orientada a la producción de leche y queso. A finales del siglo pasado este pastoreo sufrió un importante proceso de transformación que ha necesitado de nuevas instalaciones en la explotación y cambios en la propia actividad y por tanto también paisajísticos, que han afectado a los valles como a las majadas (Garayo, 2008: 15-36). Así, en el último Censo Agrario queda recogido que, de las 10.314 explotaciones con ganado herbívoro del País Vasco, en Gipuzkoa sólo el 9\% utiliza los montes comunales, siendo en Bizkaia el 17\% y en Araba/Álava el 45\%.

En el extremo meridional y de condición climática mediterránea, con el fondo escénico de la sierra de Toloño-Cantabria-Codés, la comarca denominada como Rioja Alavesa, es tierra de núcleos compactos en altozano, cereales y vid. 
Hasta este siglo ambos cultivos dibujaban un paisaje de teselas alternas, pero en la actualidad las viñas se han convertido en principal matriz de paisaje, en este caso también apoyadas por la Denominación de Origen del vino. Así, esta comarca que abarca desde el cordal de Cantabria hasta el río Ebro, con 31.580 ha y un SAU de 15.982 ha, ocupa en viñedos 13.336 ha y no llega a las 3.000 ha de cereal. A la plantación de la viña acompaña la bodega, elemento clave de una nueva cultura (Elías, 2008: 137-158) y también hito paisajístico.

En definitiva, la amalgama de los paisajes actuales que componen el territorio del País Vasco es resultado de procesos de índole natural como antrópica, de escalas de tiempo y de control de los sistemas diferente así como de ritmos de cambio diverso (figura 3).

FIGURA 3

\section{EJEMPLOS DE PAISAJES DE LA CAPV CON CARÁCTER Y RITMO DE} TRANSFORMACIÓN DIFERENTE.

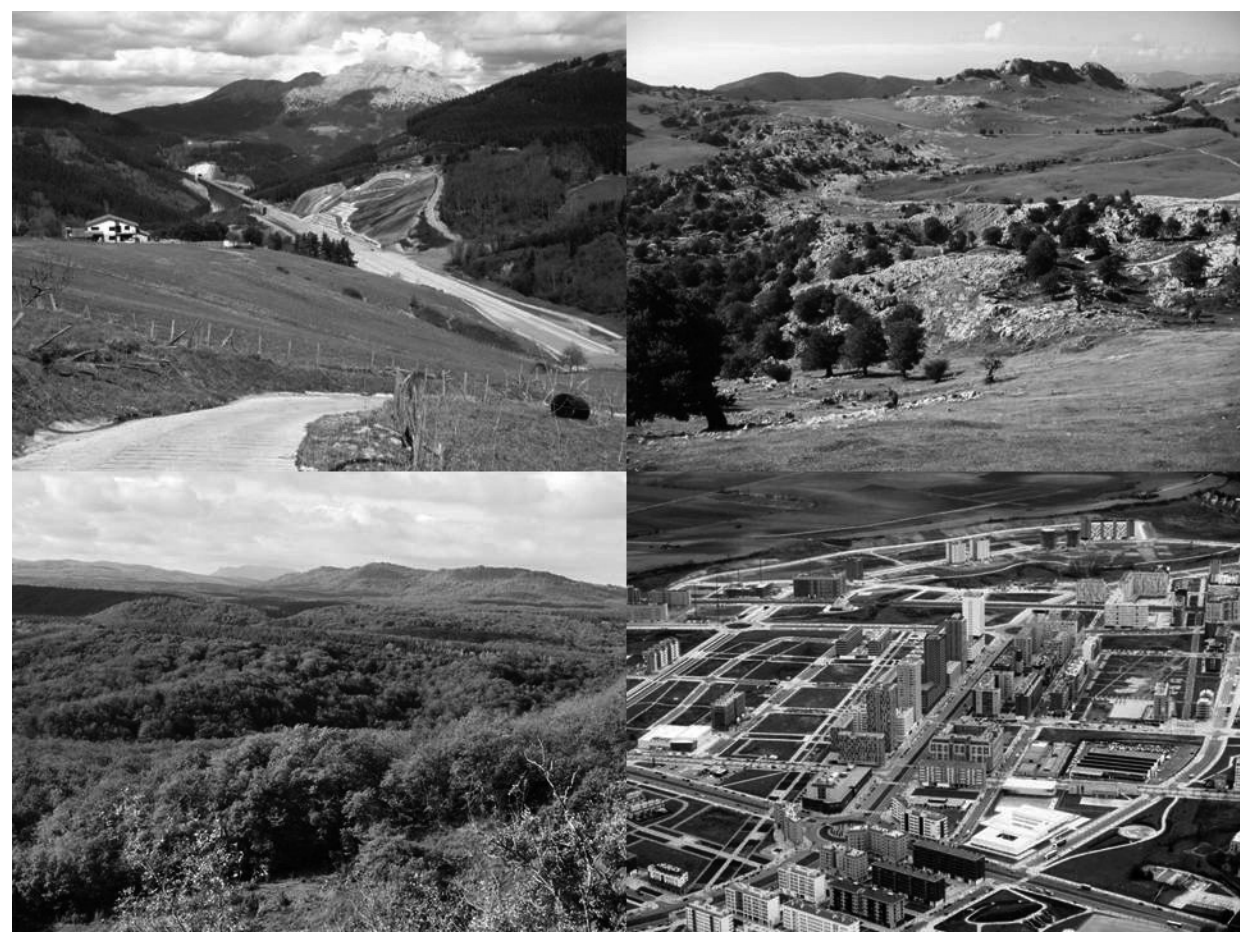

Valle agroforestal con la obra de construcción del TAV, majadas y pastos de altura del Parque Natural de Aratz-Aizkorri, bosque de Quercus Pyrenaica del P. N. de Izki y la expansión urbana de Vitoria-Gasteiz. 
ANÁlisis de los DATOS DE ocupación DEL SUELO DESDE EL Último CUARTO DEL S. XX Y QUE RECOGEN LOS CAMBIOS MÁS RECIENTES DEL PAISAJE

Para la interpretación de los datos aportados por los inventarios forestales (IFN1/IFN2/IFN3/IFN4) y su comparación con los de CORINE Land Cover (CLC1990, CLC2000 y CLC2006) es necesario en primer lugar tener presente que la unidad mínima superficial cartografiable en CLC1990 y CLC2000 es de 25 ha para el caso de la clasificación de las zonas agrícolas, forestales y humedales y sin embargo para cartografiar las superficies artificiales y de agua ésta desciende hasta 5 ha (Plata et al., 2009). En cambio en 2006 la unidad mínima superficial cartografiable es de 25 ha en todos los tipos de uso y también hay que considerar que únicamente se cartografían los elementos lineales con una anchura mayor a $100 \mathrm{~m}$.

El primer Inventario Forestal Nacional (IFN1) informa de claras diferencias de uso entre los tres territorios vascos (tabla 1): mientras Bizkaia y Gipuzkoa tenían para entonces un dominio de paisajes forestales (60\% y 57\% respectivamente, de los cuales el $80,3 \%$ y el 61,9\% correspondían a coníferas), Araba/Álava era una extensión de cultivos (39,47\%), masas forestales (35,57\%, en este caso con preeminencia de especies frondosas - 65\%-) y superficies de matorral/pastizal (21,34\%). Respecto a los datos del IFN2 en Araba/Álava se produce un aumento del suelo forestal en un $12 \%$ que se corresponde con un descenso del paisaje de matorral (9\%) por menor presión ganadera y de los espacios agrícolas (3\%). En el caso de Gipuzkoa y Bizkaia el paisaje forestal se mantiene (Bizkaia aumenta en 9.000 ha la superficie plantada de eucaliptos) y disminuye el de matorral/pastizal para aumentar en prados y cultivos. En este sentido, hay que advertir que tanto en IFN1 como en IFN2 los prados estaban incluidos en el apartado de cultivos y que en análisis pormenorizados constatan para estas fechas diferencias por tramos de altitud, con la disminución de los espacios forestales por improductivo o praderíos en el intervalo 0-400 m (Askasibar, 1997).

En la misma década, según el CORINE Land Cover (CLC 1990) Araba/ Álava tenía mayor superficie forestal que 20 años antes $(37,9 \%)$ a expensas de las superficies de matorral y un $10 \%$ menos de superficie respecto del IFN2, mientras que en Bizkaia y Gipuzkoa esta situación se invertía. Estos traspasos entre forestal y matorral no significan un cambio de uso sino distintas fases de la explotación, principalmente de coníferas (Porcal et al., 2009: 123-153). 
TABLA 1

SUPERFICIES PORCENTUALES EN LA CAPV DE LOS TIPOS DE COBERTURA DE SUELO EN LOS DIFERENTES INVENTARIOS FORESTALES NACIONALES Y EN

EL PROYECTO CORINE LAND COVER

\begin{tabular}{|c|c|c|c|}
\hline & $\begin{array}{c}\text { ARABA/ALAVA } \\
\text { Superficie Total } \\
3.037,5 \mathrm{~km}^{2}\end{array}$ & $\begin{array}{c}\text { GIPUZKOA } \\
\text { Superficie Total } \\
1.980,3 \mathrm{~km}^{2}\end{array}$ & $\begin{array}{c}\text { BIZKAIA } \\
\text { Superficie Total } \\
2.217,2 \mathrm{~km}^{2}\end{array}$ \\
\hline USO FORESTAL & Sup. $\%$ & Sup. $\%$ & Sup. $\%$ \\
\hline IFN1 (1971-1972) & 35,57 & 60,02 & 56,93 \\
\hline IFN2 (1986-1996) & 47,24 & 59,81 & 57,84 \\
\hline CLC (1990) & 37,92 & 52,49 & 45,09 \\
\hline CLC (2000) & 38,70 & 49,27 & 42,44 \\
\hline CLC (2006) & 39,34 & 52,39 & 45,38 \\
\hline IFN (2005) & 46,63 & 62,96 & 58,97 \\
\hline IFN (2010) & 46,40 & 62,80 & 59,41 \\
\hline PRADOS & Sup. $\%$ & Sup. $\%$ & Sup. $\%$ \\
\hline IFN1 (1971-1972) & - & - & - \\
\hline IFN2 (1986-1996) & - & - & - \\
\hline CLC (1990) & 6,42 & 24,05 & 25,10 \\
\hline CLC (2000) & 6,39 & 23,75 & 24,69 \\
\hline CLC (2006) & 6,40 & 23,90 & 24,71 \\
\hline IFN (2005) & 5,10 & 18,46 & 18,43 \\
\hline IFN (2010) & 5,11 & 19,14 & 17,76 \\
\hline MATORRAL/PASTIZAL & Sup. $\%$ & Sup. $\%$ & Sup. $\%$ \\
\hline IFN1 (1971-1972) & 21,34 & 17,77 & 13,40 \\
\hline IFN2 (1986-1996) & 12,11 & 10,58 & 9,76 \\
\hline CLC (1990) & 18,48 & 18,24 & 23,22 \\
\hline CLC (2000) & 17,64 & 21,31 & 25,78 \\
\hline CLC (2006) & 17,22 & 18,26 & 23,14 \\
\hline IFN (2005) & 11,72 & 8,63 & 10,46 \\
\hline IFN (2010) & 15,02 & 9,07 & 11,07 \\
\hline CULTIVOS & Sup. $\%$ & Sup. $\%$ & Sup. $\%$ \\
\hline IFN1 (1971-1972) & 39,47 & 16,78 & 21,53 \\
\hline IFN2 (1986-1996) & 36,01 & 23,72 & 23,77 \\
\hline CLC (1990) & 34,00 & 0,02 & 0,23 \\
\hline CLC (2000) & 33,69 & 0,02 & 0,24 \\
\hline CLC (2006) & 33,75 & 0,03 & 0,25 \\
\hline IFN (2005) & 27,73 & 0,75 & 0,94 \\
\hline IFN (2010) & 27,36 & 0,87 & 0,94 \\
\hline ARTIFICIAL & Sup. $\%$ & Sup. $\%$ & Sup. $\%$ \\
\hline IFN1 (1971-1972) & - & - & - \\
\hline IFN2 (1986-1996) & - & - & - \\
\hline CLC (1990) & 1,75 & 4,02 & 4,59 \\
\hline CLC (2000) & 2,13 & 4,42 & 5,15 \\
\hline CLC (2006) & 2,03 & 4,27 & 4,96 \\
\hline IFN (2005) & 3,82 & 6,10 & 8,13 \\
\hline IFN (2010) & 4,32 & 6,52 & 8,99 \\
\hline
\end{tabular}

Fuente: Inventario Forestal Nacional (1972/1986-1996/2005/2010) y Corine L.C. (1990/2000/2006). 


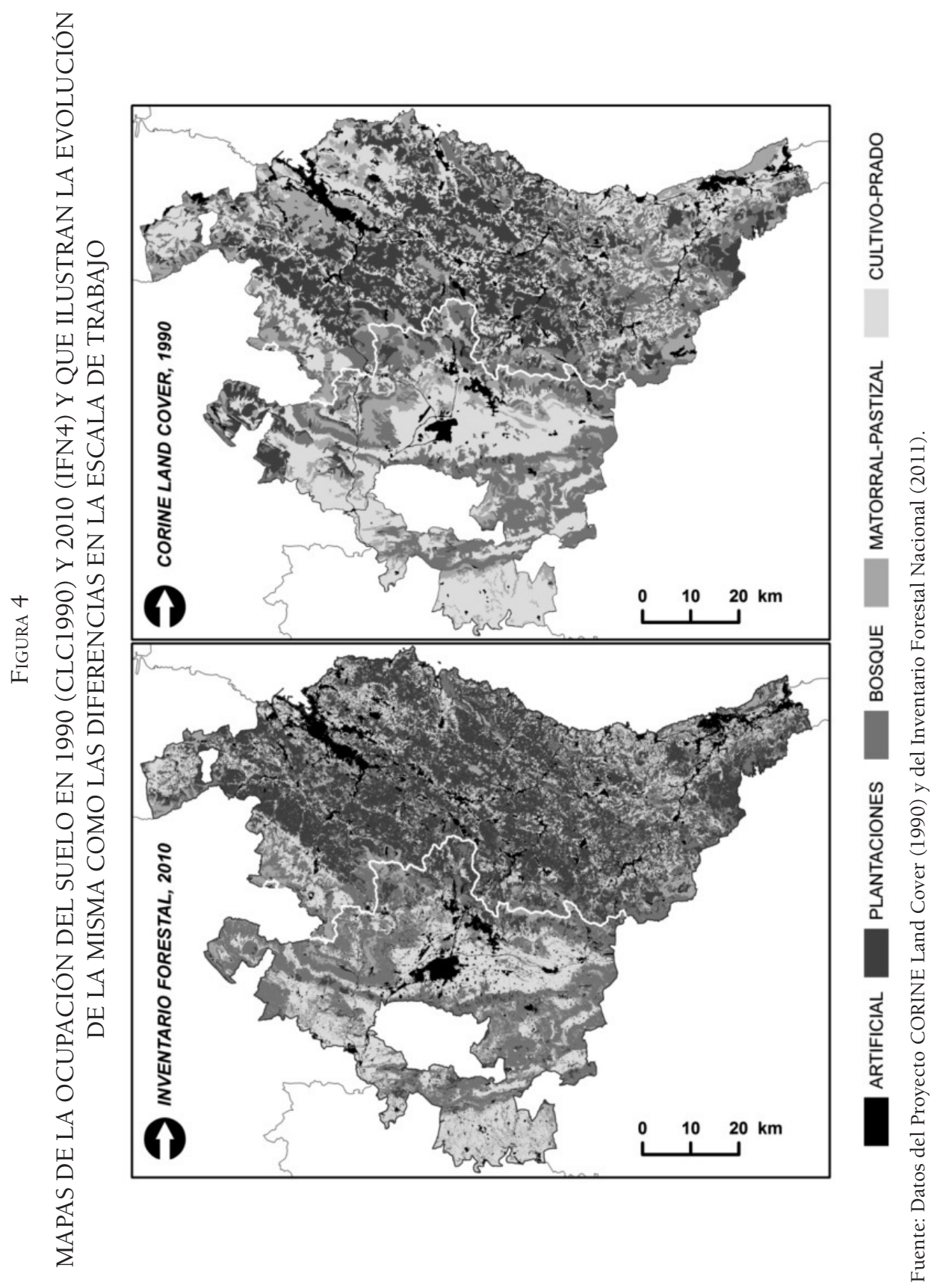

Estudios Geográficos, Vol. LXXIX, 284, pp. 85-113, enero-junio 2018

ISSN: 0014-1496, eISSN: 1988-8546, doi: https//doi.org/10.3989/estgeogr.201804 
En los últimos Inventarios forestales (2005-2011) hay de nuevo un aumento de suelo forestal en todos los casos y significativo con más del 10\% para Bizkaia y Gipuzkoa respecto del CLC. La escala de este trabajo fue de 1:10.000 y por tanto de mayor detalle, pudiendo distinguirse ámbitos de uso que en CORINE quedan por debajo de la unidad mínima de 25 ha (figura 4) y así las manchas del mosaico forestal con otros usos característica principalmente de muchos valles de Bizkaia y Gipuzkoa y la vertiente atlántica de Araba/Álava han quedado infravaloradas. Por su parte los paisajes de matorral/pastizal tienen una clara merma, ya que han sido los principales beneficiarios de ese tratamiento de escala.

Respecto a los paisajes de praderío y cultivos, ya se ha señalado que ambos tipos están recogidos en un único epígrafe en los primeros inventarios. Pero es clara la dicotomía entre Araba/Álava con un mayor porcentaje agrario (39,5\%) y Bizkaia y Gipuzkoa menor (21,5 y 16,8\% respectivamente y correspondientes a prados). En el CLC 1990 (ya en prados) ambas superficies aumentan y sobre todo lo hacen en Bizkaia y Gipuzkoa entendiendo que esta ganancia es a expensas del suelo forestal, pero no porque se haya producido un traspaso sino que, como en el caso anterior, se trata de un problema de la escala de detalle. De cualquier modo Araba/Álava pierde paisaje agrario (39,5\% en IFN1 y 27,36\% en IFN4) para pasarlo a artificial (3,14\% en IFN1 a 4,32\% en IFN4) o forestal (35,6\% en IFN1 a 46,4\% en IFN14). Para los prados y segundo uso de suelo en cobertura en Gipuzkoa y Bizkaia, es destacable el aumento que se produce entre el IFN1 y el IFN2 para luego mantenerse en el período 1990-2006 y posteriormente descender de forma ligera, no tanto por el constatado retroceso del sector agroganadero y la infrautilización de los ámbitos marginales (Murua et al., 2012: 63-91) a pesar de las políticas de desarrollo rural (Alberdi, 2014), como por la demanda urbanística.

En este sentido, entre 1990 y 2006 según CORINE el suelo artificial aumentó en más de 800 ha en Araba/Álava y Bizkaia, y en casi 500 ha en Gipuzkoa. Si la comparación se realiza con el inventario de 2010, en Araba/ Álava se dobla el suelo artificial en menos de un lustro. Respecto a Gipuzkoa los valores de artificialización también aumentan pero en menor medida que Araba/Álava y Bizkaia. Esta última es la que recoge en el último inventario casi un $9 \%$ de superficie artificial seguida de Gipuzkoa (6,5\%) y por último Araba/Álava con un 4,3\%. Este improductivo artificial aumenta en los tres Territorios Históricos a costa principalmente de los espacios de praderío y cultivos (figura 5). 
FIGURA 5

EJEMPLOS DEL CAMBIO EN LA OCUPACIÓN DEL SUELO (2002-2015)
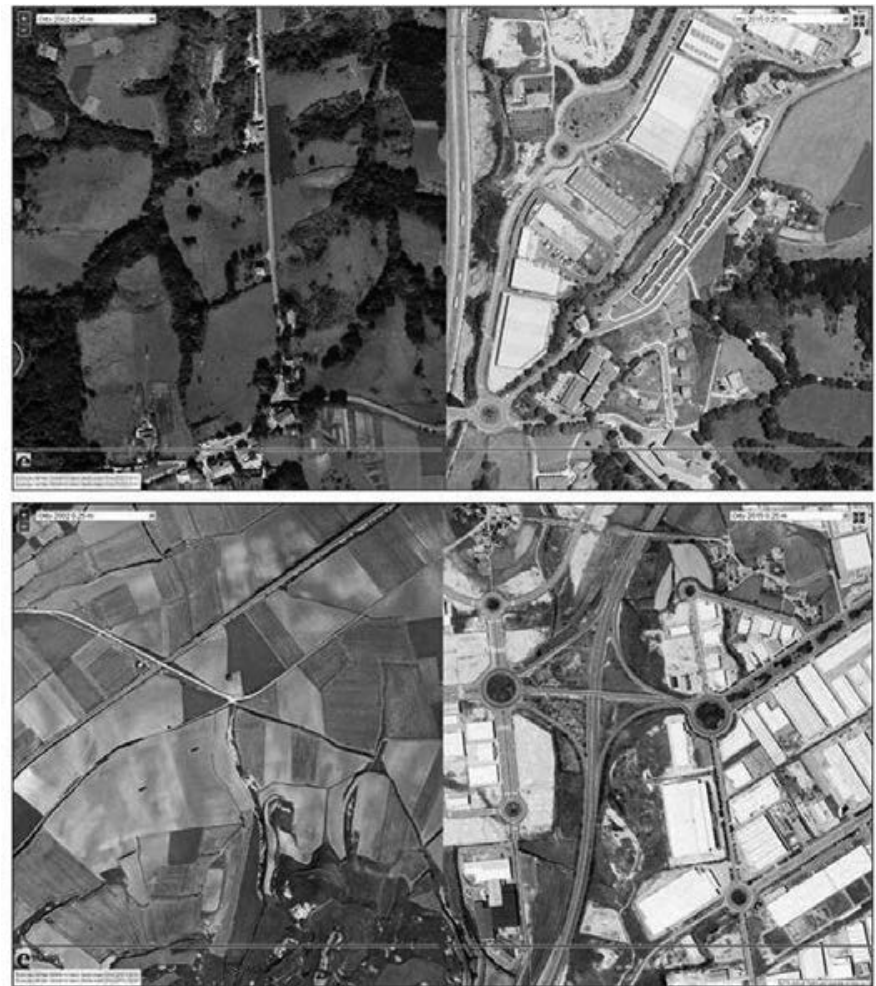

Fuente: Visor IDE de Euskadi. Ejemplos de la vertiente cantábrica (arriba) y mediterránea (abajo).

LA CONSIDERACIÓN DEL PAISAJE Y SU VALOR EN LAS DIFERENTES ESCALAS TERRITORIALES Y QUE ATAÑEN A LA CAPV.

Como expresaba Gómez Tejedor (1974: 10) «el sentimiento por el paisaje es algo moderno». Los orígenes de la consideración del paisaje y su valor a nivel europeo se encuentran en la $1^{a}$ Conferencia Internacional sobre Protección de la Naturaleza (Berna 1913) y el $1^{\circ}$ Congreso Internacional sobre Protección de Flora y Fauna, Parajes y Monumentos Naturales (París 1923). En éste se presentaron las políticas de conservación de los espacios naturales que venían desarrollando diversos países y entre ellos España, con la primera Ley de Parques Nacionales en 1916 (Iniesta, 2001: 408). El País Vasco, atendiendo a la realidad paisajística 
de su territorio no tenía razón de belleza para que su conservación fuera considerada de interés general para la nación. Posteriormente, la UNESCO aprueba en 1972 la Convención Internacional para la protección del Patrimonio Mundial Natural y Cultural y en este marco en el País Vasco están catalogados como Patrimonio de la Humanidad (Bien cultural) el Arte Rupestre Paleolítico del Norte de España que incluye tres cuevas en esta Comunidad (Altxerri y Ekain en Gipuzkoa y Santimamiñe en Bizkaia, 2008), el Puente de Bizkaia (2006) y las rutas costera y vasco-riojana del Camino de Santiago (Caminos del Norte de España, 2015).

Por su parte, en el Estado el Instituto Nacional para la Conservación de la Naturaleza publicó en 1977 el Inventario Nacional de Paisajes Sobresalientes. En él es considerado como Paisaje Sobresaliente el 11,8\% de la superficie del País Vasco (Araba/Álava 3,8\%, Bizkaia 1,6\% y Gipuzkoa 6,4\%) (ICONA, 1977).

En la escala autonómica, el traspaso competencial legislativo, entre otras, en materia de conservación de la naturaleza como de ordenación territorial, ha tenido como consecuencia en el primer caso (Ley 16/1994 de Conservación de la Naturaleza — modificada por Ley $1 / 2010$ - y Ley de protección y Ordenación de la Reserva de la Biosfera de Urdaibai 5/1989) la declaración de una amplia variedad de espacios protegidos. En este contexto hay que destacar que el interés por conservar los ecosistemas por parte de la administración ha ido acompañado por el de conocer la percepción de esos paisajes a proteger. Así, en la década de los 80 se realizaron por primera vez entrevistas y encuestas de percepción del paisaje en los estudios que precedieron a la declaración de los diferentes espacios protegidos (e. g. Aranburu, 1983). Espacios que en la actualidad suponen un $37,1 \%$ del territorio y para los cuales se han desarrollado diversos instrumentos de ordenación y gestión que atienden también al paisaje.

En la década de los 90 y tras la elaboración de la Cartografía de Paisaje de la CAPV se realizaron diversos estudios de valoración del paisaje por el público y expertos, locales y foráneos (Ruíz, 1993). En ellos, además de la determinación de preferencias sobre los distintos tipos de paisaje que componen el territorio, también se identificaban los principales elementos del paisaje prototípico vasco (Ormaetxea et al., 1992; De Lucio et al., 1994).

Por su parte, también se ha desarrollado una política ambiental (Ley General 3/1998 de Protección del Medio Ambiente del País Vasco) dentro de la cual se encuentran la Estrategia y Programas Marco Ambientales. Entre los objetivos generales fijados en la primera (Gobierno Vasco, 2002) se encuentra el de conservar y proteger los ecosistemas, las especies y el paisaje, y en concreto, entre otros, "promover la protección de los recursos paisajísticos, potenciando en particular la conservación de los paisajes singulares y aquellos 
de alto componente de calidad y naturalidad». Así, en este marco se elaboró el Anteproyecto de Paisajes Singulares y Sobresalientes de la CAPV en el cual se presentó una propuesta de Catálogo con un total de $2.549 \mathrm{~km}^{2}$ catalogados (35,3\% de la CAPV) y de los cuales el $55,4 \%$ correspondían a Araba/Álava, $25,6 \%$ a Gipuzkoa y 18,8\% a Bizkaia (Aranburu et al., 2006). En la misma línea de actuación la Diputación Foral de Araba/Álava (2005) también realizó un Catálogo de Paisajes Singulares y Sobresalientes en el que resultó calificado como tal un $57 \%$ de su territorio. En ambos Catálogos, además de variables métricas, se consideraron los resultados de las encuestas de percepción realizadas en la década anterior y una nueva consulta a través de Internet cuyos datos permitieron elaborar el Catálogo definitivo (Askasibar, 2009).

Respecto a la ordenación territorial, la CAPV cuenta con La Ley 4/1990 de Ordenación del Territorio cuya Directriz de Medio Físico recoge: «es preciso catalogar las zonas visuales, que deben tener un tratamiento paisajístico especial, asimismo, los hitos y singularidades paisajísticas naturales deben quedar inscritos en perímetros que tengan en cuenta su cuenca visual» (Gobierno Vasco, 1997. Boletín Oficial del País Vasco, Suplemento al no 29: 6). Sus instrumentos legales son los Planes Territoriales Parciales y los Planes Territoriales Sectoriales y de ellos destacan por su tratamiento del paisaje, el de la Energía Eólica y el Agroforestal. Además, con la adhesión en 2009 al CEP, el ente administrativo autonómico inicia una estrategia para incorporar la variable paisajística no sólo en la conservación sino en el conjunto de la planificación territorial y teniendo en cuenta la percepción de su población (Gobierno Vasco, 2013). Así, en 2012 fue aprobado el Anteproyecto de Ley de Paisaje en el que se establecían para garantizar la protección, gestión y ordenación de los paisajes, los siguientes instrumentos: Catálogos del paisaje, Directrices del paisaje, Planes de Acción del paisaje y Estudios de Integración paisajística (BOPV, 2011). En ese marco se elaboraron tres Catálogos de Paisaje (Áreas Funcionales de Balmaseda-Zalla, Zarautz-Azpeitia, Laguardia) en los que además de la labor de análisis y diagnóstico con propuestas metodológicas diversas, se llevó a cabo un proceso de participación (Gobierno Vasco, 2013) que permitió reconocer los paisajes mejor valorados, sus fortalezas, los elementos más valiosos y los más degradantes; recoger sugerencias de medidas para mejorar esos paisajes y en una segunda etapa determinar cuáles eran los principales objetivos de calidad y las medidas que se pudieran implementar. Este Anteproyecto no llegó a Ley pero sí fue aprobado el Decreto de Protección, Gestión y Ordenación del Paisaje con objetivos similares (Gobierno Vasco, 2014) y que en este momento, además de la elaboración de nuevos Catálogos de paisaje (Área Funcional de Donostia-San Sebastián) y las Determinaciones 
de Paisaje para los Catálogos ya finalizados, está propiciando la realización de numerosos Planes de Acción del Paisaje a escala municipal (Gobierno Vasco, 2015) y ha publicado la Guía para la elaboración de Estudios de Integración Paisajística (Gobierno Vasco, 2016a).

\section{Conclusiones}

Este trabajo ha recogido de forma sucinta aquellas características del ámbito físico que condicionan el carácter de los paisajes de la Comunidad Autónoma del País Vasco y ha realizado un recorrido también diacrónico y resumido de la adaptación antrópica a esos espacios a través de la actividad y la ocupación del suelo y que explican la diversidad paisajística actual. En esta primera aportación resulta que sobre la homogeneidad cromática descrita por algunos autores: «Así todo es verde en Vasconia, en donde el roquedo es complemento, discretamente manifestado, del bosque del matorral, de la pradería y de los cultivos» (HernándezPacheco, 1934: 54) hay multitud de texturas, unas, como se ha visto, de carácter secular y otras de reciente cuño y que han sido identificadas en este trabajo. En su materialización se ha recurrido al método geográfico clásico (Muñoz, 1989: 54) queriendo reivindicar la actualidad del mismo y siendo conscientes del discurso selectivo utilizado (Corbera, 2016: 19).

Por su parte, y como segunda aportación, el análisis cuantitativo y comparativo de los datos de ocupación de suelo de las últimas décadas, además de destacar aspectos metodológicos y de interpretación de resultados de las fuentes de datos consultadas, ha permitido determinar a escala provincial cuáles han sido los cambios de ocupación y por tanto paisajísticos desde la década de 1970. De forma pormenorizada queda de manifiesto cómo el modelo territorial en el País Vasco ha propiciado el mantenimiento e incluso el aumento de la cobertura forestal y en cambio los prados y cultivos han visto mermada su extensión a favor del suelo artificial; mientras, los pastizales y matorrales lo han hecho en beneficio del bosque. De los cambios recogidos, si bien todos tienen significación paisajística, queremos destacar, la artificialización del territorio, que ya llega al medio millar de $\mathrm{km}^{2}$. Una artificialización, que según el seguimiento espacial realizado, no en todos los casos ha tenido un carácter compacto en torno a los espacios urbanos sino que ha requerido de la edificación en los núcleos rurales dispersos que caracterizan este espacio, de la construcción de nuevas tramas de comunicación (e.g. Tren de Alta Velocidad) y en general de la ocupación de suelos de condición inicial principalmente agroganadera. Además, el territorio de la CAPV se encuentra 
muy compartimentado visualmente, con 621 cuencas visuales de las cuales el $50 \%$ tiene menos de $8 \mathrm{~km}^{2}$ de capacidad visual y su relieve tiene un 35\% de su superficie con valores superiores al 30\% de pendiente, de tal manera que hay una alta capacidad del contenido visual. Un contenido que, como en el caso de la red de comunicación (entre 2005 y 2013 se artificializaron 602 ha de infraestructura viaria y 305,55 ha del TAV), ya se ha referido, transcurre por laderas altamente expuestas. Desde la perspectiva visual como de la sostenibilidad, el modelo territorial del futuro (Gobierno Vasco, 2016b) debe considerar este hecho no abordándolo únicamente con labores de integración paisajística sino intentando no agotar el soporte que sustenta a los usos y los paisajes o que se conviertan en espacios de amenaza o perturbación (Redacción DV, 2016).

Por último, el análisis se ha ocupado de recoger el relato de la consideración del paisaje en la CAPV: como patrimonio de carácter universal con la designación de varios enclaves como Patrimonio Mundial Cultural, como valor de calidad reconociendo los Paisajes Singulares y Sobresalientes a nivel estatal, autonómico y provincial, como valor de conservación y de protección, como hito visual y elemento percibido por la población y por tanto a considerar en la ordenación territorial. El seguimiento de toda esta labor permite concluir con una última aportación y es que las políticas administrativas han sido conscientes de la importancia del paisaje para el territorio y su sociedad; que ha valorizado una parte significativa del territorio y en diferentes sentidos y escalas (desde los Parques Naturales y la regeneración de grandes espacios degradados o en declive hasta la catalogación de los Árboles Singulares o los Lugares de Interés Geológico, entre otros), en beneficio también por ende del propio paisaje; que ha sabido valorar su calidad e incluso conocer algunas pautas de la percepción de los diferentes paisajes. Pero faltaba cómo objetivarlo normativa e instrumentalmente, cómo actuar no sobre el territorio sino sobre el paisaje.

Desde la adhesión al CEP en 2009 y la aprobación en 2014 del Decreto de Protección, Gestión y Ordenación del Paisaje tenemos ese nuevo marco en el que la participación ciudadana es pilar fundamental. Los retos se encuentran en este momento en cómo, si la intención de tener un paisaje de calidad se mantiene, desarrollar metodologías de análisis y diagnóstico paisajístico óptimas que engarcen con la situación actual de la ocupación del suelo y de su demanda, e implementar con instrumentos y actuaciones los objetivos de calidad que se asume en esta nueva coyuntura del CEP puede requerir la población. En definitiva qué y cómo hacer con el paisaje en la CAPV. 


\section{Agradecimientos}

Este trabajo ha contado con la aportación del Grupo de Investigación Consolidado del Gobierno Vasco IT622-13 y el Proyecto de Investigación MINECO/ FEDER, UE CSO2015-65787-C6-3-P Paisajes culturales de la lista de patrimonio mundial. Claves para la identificación y criterios para gestión de paisajes agroganaderos, mineros e industriales de España atlántica.

\section{BiBLIOGRAFÍA}

A.A.V.V. (1979): Geografía General de Euskal Herria.Luis Haranburu Editor. DonostiaSan Sebastián, Volúmenes I-VII.

A.A.V.V. (1980): Geografía General del País Vasco. Editorial La Gran Enciclopedia Vasca. Bilbao. Facsimil de la $1^{\text {era }}$ edición dirigida por F. Carreras Candi (1910), Volúmenes I-XII.

Aguirre, I. (1979): Eusko Lurra. Geografía del País Vasco. Editorial Elexpuru Hnos, Zamudio, Bilbao, 397 pp.

Ainz, M.J.; Aldai,P.; Ollero, A.; Ormaetxea, O.; Portugal, J.A. (1999). "País Vasco" en García, J.M. y Sotelo, J.A. (ed.), La España de las Autonomías, Madrid, Editorial Síntesis, pp. 605-646.

Alberdi, J.C. (1993): Desarrollo rural en el País Vasco: del programa de Agricultura de Montaña a las Asociaciones de Desarrollo Rural, Informes Técnicos 115, Departamento de desarrollo económico y competitividad, Gobierno Vasco, 249 pp.

Antrop, M. (2006): "From holistic landscape synthesis to transdisciplinary landscape management", en TRESS, B., TRESS, G., FRY, G., OPDAM, P. (eds.), From landscape research to landscape planning: aspects of integration, education and application Dordrecht, Springer, Wageningen UR Frontis Series 12, 27-50 pp.

Aranburu, A. (dir. téc.) (1983): Estudio del medio físico de Txingudi. Gobierno Vasco/ Sociedad de Ciencias Aranzadi, Informe inédito, 267 p.

Aranburu, A., Fernández de Mendiola, J.A., Askasibar, M., De Francisco, M. (2006): "Política de paisaje en el País Vasco", Euskonews \& Media, 332, http://www.euskonews.com/0332zbk/menu.html (Fecha de consulta: 8/2/2015).

Askasibar, J. (1997): "La situación forestal de cara al siglo XXI", Revista Internacional de Estudios Vascos, XLII/2, pp. 309-323.

Askasibar, M. (2009): "País Vasco", en Jiménez, L. (dir.), Patrimonio natural, cultural y paisajístico. Claves para la sostenibilidad territorial, Alcalá de Henares, Observatorio de la Sostenibilidad en España, pp. 124-126.

Barnolas, A., Pujalte, V. (2004): "La Cordillera Pirenaica", en Vera, J. A. (ed.), Geología de España, Madrid, Sociedad Geológica de España, Instituto Geológico y Minero de España, pp. 233-241.

Baroja, P. (1953): El País Vasco, Barcelona, Ediciones Destino, 520 pp. 
Bikandi, J. J. (1982): "Titularidad, gestión y uso del monte en Euskalerria”, en Ayerbe, E. (ed.), Mendiak. Montes de Euskal Herria, Vol. III, Donostia-San Sebastián, Etor, pp. 62-74.

Bilbao, L. M., Fernández de Pinedo, E. (1984): "La producción agrícola en el País Vasco peninsular, 1537-1850: tendencia general y contrastes comarcales. Una aproximación", Vasconia. Cuadernos de Historia-Geografía, 2, pp. 83-198.

Boletín Oficial del País Vasco, BOPV nº 67, de 6 de abril de 2011. https://www.euskadi.eus/bopv2/datos/2011/04/1101979a.pdf (Fecha de consulta: 27/1/2016).

Confederación de Forestalistas del País Vasco. (2012): "El Inventario Forestal de 2011 ratifica el crecimiento de la superficie arbolada y existencias en Euskadi", Revista Basogintza, 82, pp. 30-33.

Conseil de L'Europe (2000): “Convention européenne du paysage”. Florencia: STE 176. https://rm.coe.int/CoERMPublicCommonSearchServices/DisplayDCTMContent? documentId=09000016802f3fbd (Fecha de consulta: 3/2/2015).

Constanza, R., D’Arge, R., De Groot, R., Farber, S., Grasso, M., Hannon, B., Limburg, K., Naemm, S., O'neill, R., Paruelo, J., Raskin, R., Sutton, P. and Van Den Belt, M. (1997): "The value of the world's ecosystem services and natural capital", Nature, 387, pp. 253-260.

Corbera, M. (2016): "El paisaje, su patrimonialización y el beneficio economico", Investigaciones Geográficas, 65, pp. 9-24.

Corine Land Cover (1990, 2000, 2006), European Environment Agency/Agencia Europea del Medio Ambiente. Centro Nacional de Información Geográfica. Ministerio de Fomento. https://www.ign.es/ign/layoutIn/coberturaUsoSuelo.do (Fecha de consulta: 17/2/2015).

Cruz, L., Español, I. (2007): "Los paisajes de la industrialización”, Bienes culturales: revista del Instituto del Patrimonio Histórico Español, 7, pp. 119-131.

Cruz, L., Español, I. (2009): El paisaje. De la percepción a la gestión, Madrid, Liteam, $255 \mathrm{pp}$.

De Groot, R. (2006): "Function-analysis and valuation as a tool to assessland use conflicts in planning for sustainable, multi-functional landscapes", Landscape and urban Planning, 75, pp. 175-186.

De Lucio, J. V., Ormaetxea, O. (1994): "Relaciones entre caracterización ecológica y percepción del paisaje. Aplicación a la valoración del paisaje vasco cantábrico", en Fernández, G., Rubio, P. (eds.), Paisaje y Medio Ambiente, Monografies del l'Equip, 5, Universidad de Barcelona, pp. 113-122.

Díaz de Durana, J. R. (1998): "Transformaciones en la titularidad y aprovechamiento de los seles en Gipuzkoa (1440-1550)", Zainak, 17, pp. 19-31.

Diputación Foral de Álava (2005). Catálogo de Paisajes Singulares y Sobresalientes del Territorio Histórico de Álava, Departamento de Urbanismo y Medio Ambiente. http://www.araba.eus/cs/Satellite? c=Page\&cid=1 193046487485\&pagename=Dipu tacionAlava\%2FPage\%2FDPA_contenidoFinal (Fecha de consulta: 3/5/2016). 
Elias, L. V. (2008): "Paisaje del viñedo", Pasos: Revista de turismo y patrimonio cultural, $\mathrm{VI} / 2$, pp. 137-158.

EUSTAT (2015). Euskal Estatistika Erakundea-Instituto Vasco de Estadística. Suelo de actividades económicas según territorio 2015. http://www.eustat.eus/movil/ elementos/ele0005400/ti_Suelo_de_actividades_economicas_de_la_CA_de_ Euskadi_por_tipo_segun_territorio_historico_Ha_2014/ (Fecha de consulta: 18 de mayo de 2016).

Farina, A. (2011): Ecología de paisaje. Publicaciones Universidad de Alicante, 688 pp.

Fernández de Pinedo, E. (1974): Crecimiento económico y transformaciones sociales del País Vasco 1100/1850, Madrid, Siglo XXI de España Editores, 500 pp.

Frolova, M.; Menor, J.; Cancer, L. (2003): "Paisaje en las políticas de Francia y España”, Estudios Geográficos, 64 (253), pp. 605-621.

Frolova, M. (2009): "La evolución reciente de las políticas de paisaje en España y el Convenio Europeo del Paisaje", Proyección de la Universidad Nacional de Cuyo, $\mathrm{n}^{\circ}$ 6. www.cifot.com.ar/proyeccion/

Garayo, J. M. (2008): "Lobo y pastoreo extensivo de ganado ovino en el País Vasco", Lurralde, 31, pp. 15-36.

García de Cortazar, F., Lorenzo, J. M. (2000): Historia del País Vasco: de los orígenes a nuestros días, San Sebastián, Txertoa, 319 pp.

Gobierno Vasco (1997): "Directrices de Ordenación Territorial de la Comunidad Autónoma del País Vasco. Decreto 28/1997”. Boletín Oficial del País Vasco, Suplemento al no 29 (12 de febrero de 1997).

Gobierno Vasco (2002): Programa Marco Ambiental de la Comunidad Autónoma del País Vasco (2002-2006). Estrategia Ambiental Vasca de Desarrollo Sostenible 2002-2020, Vitoria-Gasteiz, Sociedad Pública de Gestión Ambiental-IHOBE, 94 pp.

Gobierno Vasco (2013): Memoria de participación. http://www.ingurumena.ejgv.euskadi.eus/r49-cpaisaia/es/contenidos/informacion/ paisaia_2011/es_paisaia/participacion.html (Fecha de consulta: 15/1/2016).

Gobierno vasco (2014): Decreto sobre protección, gestión y ordenación del Paisaje. http://www.ingurumena.ejgv.euskadi.eus/r49-cpaisaia/es/contenidos/informacion/ paisaia_2011/es_paisaia/ley.html (Fecha de consulta: 8/7/2015).

Gobierno Vasco (2015): Adjudicación de subvenciones para la redacción de Planes de Acción de Paisaje, BOPV n 213.

http://www.euskadi.eus/gobierno-vasco/-/noticia/2015/adjudicacion-de-subvencionespara-la-redaccion-de-planes-de-accion-del-paisaje/ (Fecha de consulta: 23/3/2016).

Gobierno Vasco (2016a): Guía para la elaboración de Estudios de Integración Paisajística. http://www.ingurumena.ejgv.euskadi.eus/contenidos/informacion/integracion_paisajistica/es_def/adjuntos/Guia\%20paisaje_FINAL.pdf (Fecha de consulta: 20/05/2017).

Gobierno Vasco (2016b): Revisión de las Directrices de Ordenación Territorial de la CAPV. http://www.euskadi.eus/web01-s2ing/es/contenidos/informacion/revision_dot/es_ def/index.shtml (Fecha de consulta: 20/6/2016). 
Gómez Orea, D. (2003): Ordenación territorial, Madrid, Ediciones Mundi-Prensa, Editorial Agrícola Española, 704 pp.

Gómez Tejedor, J. (1974): El paisaje natural, Bilbao: Caja de Ahorros Vizcaína, Colección Temas Vizcaínos, 1, 59 pp.

Gómez, J., Riesco, P. (2010): Marco conceptual y metodológico para los paisajes españoles. Aplicación a tres escalas españoles, Sevilla, Consejería de Obras Públicas y Vivienda, Centro de Estudios Paisaje y Territorio, 467 pp.

Hernández-Pacheco, E. (1934): El paisaje en general y las características del paisaje hispano. Academia de Ciencias exactas, Físicas y Naturales, Madrid, C. Bermejo, impresor, 64 pp.

Hervás, J. (2009): Ordenación del Territorio, Urbanismo y Protección del Paisaje. Barcelona, Editorial Bosch, 424 pp.

ICONA (1977): Inventario Nacional de Paisajes Sobresalientes II. Serie Monografías 6, Madrid, Servicio de Publicaciones Agraria, Ministerio de Agricultura, 533 pp.

Iniesta, P. (2001):"Parques Nacionales: crónica bibliográfica de su régimen jurídico", Observatorio Medioambiental, 4, pp. 407-414.

IDE de Euskadi. Infraestructura de Datos Espaciales. Seles. http://www.geo.euskadi. eus/seles-geocuriosidad/s69-geocont/es/ (Fecha de consulta: 5/4/2016).

Instituto Nacional de Estadística INE. Censo Agrario 2009. http://www.ine.es/CA/ Inicio.do (Fecha de consulta: 6/4/ 2016).

Inventario Forestal Nacional (IFN 1) (1971-1972), Ministerio de Agricultura. Instituto Nacional para la Conservación de la Naturaleza. Madrid. http://www.magrama. gob.es/es/biodiversidad/servicios/banco-datos-naturaleza/informacion-disponible/ primer_inventario_nacional_forestal.aspx (Fecha de consulta: 6/6/2015).

Inventario Forestal Nacional (IFN2) (1986-1995), Ministerio de Medio Ambiente. Dirección General para la Biodiversidad. Publicaciones del Organismo Autónomo Parques Nacionales. Madrid. http://www.magrama.gob.es/es/biodiversidad/servi cios/ banco-datos-naturaleza/informacion-disponible/ifn2.aspx (Fecha de consulta: 6/6/2015).

Inventario Forestal Nacional (IFN3) (1997-2007), Dirección General de Medio Natural y Política Forestal, Ministerio de Medio Ambiente y Medio Rural y Marino. http://www.magrama.gob.es/es/biodiversidad/servicios/banco-datos-naturaleza/ informacion-disponible/ifn3.aspx (Fecha de consulta: 6/6/2015).

Inventario Forestal Nacional (IFN4) (2010-2011), Ministerio de Agricultura, Alimentación y Medio Ambiente. http://www.euskadi.eus/contenidos/informacion/ inventario_forestal_2011/es_agripes/index.shtml (Fecha de consulta: 6/6/2015).

ITGE (1989): Mapa Geológico de España. Escala 1:200.000. Bermeo/Bilbao, Madrid, Instituto Tecnológico GeoMinero de España, 208 pp.+ mapa.

Kaplan, S. (1987): "Aesthetic, affect and cognition; environmental preference from evolutionary perspective", Environment and Behavior, 19, pp. 3-32.

Lambin, E., Turner, B.L., Geist, H., Agbola, S., Angelsen, A., Bruce,, J., Coomes, O., Dirzo, R., Fischer, G., Folke, C., George, P.S., Homewood, K., Imberbon, J., Lee- 
mans, R., Li X., Moran, E., Mortimore, M., Ramakrishnan, P.S., Richards, J, Skanes, H., Steffen, W., Stone, G., Svedin, U., Veldkamp, T., Vogel, C., Xu, J. (2001): "The causes of land-use and land-cover change: moving beyond myths", Global Environmental Change, 11, pp. 261-269.

Loidi, J., Biurrun, I., Campos, J. A., García-Mijangos, I., Herrera, M. (2011): La vegetación de la Comunidad Autónoma del País Vasco. Leyenda del mapa de series de vegetación a escala 1:50.000, Leioa, Universidad del País Vasco, 197 pp.

MAGRAMA (2013): Atlas de los paisajes agrarios de España. Tomo I, Madrid, Ministerio de Agricultura, Alimentación y Medio Ambiente, 501 pp.

Makarow, M., Rodríguez, Á., Zic-Fuchs, M., Caball, M. (2010): "Landscape in a changing World", Science Policy Briefing, 41.

http://www.esf.org/fileadmin/Public_documents/Publications/SPB41_Landscape_ ChangingWorld.pdf (Fecha de consulta: 26/3/2016).

Mata, R. (2000): "Los orígenes de la conservación de la naturaleza en España", en Martínez de Pisón, E. (dir.), Estudios sobre el paisaje, Madrid, Universidad Autónoma de Madrid, Fundación Duques de Soria, pp. 259-279.

Mata, R., Galiana, L., Fernández, S., Lacasta, P., López, N., Molina, P., Sanz, C., Allende, F. (2009): "Evaluación del paisaje de la Comunidad de Madrid: de la protección a la gestión territorial", Urban, 14, pp. 34-57.

Meaza, G.; Ruíz, E. (1994-1998): Geografía de Euskal Herria. Editorial Ostoa-Etor, Lasarte-Oria, Volúmenes I-V.

Michel, M., Gil, L. (2013): La transformación histórica del paisaje forestal en la Comunidad Autónoma de Euskadi, Vitoria-Gasteiz, Servicio Central de Publicaciones del Gobierno Vasco, Colección LUR, 18, 476 pp.

Muñoz, J. (1989): "Paisaje y Geografía", Arbor, Ciencia, Pensamiento y Cultura, CXXII/518-519, pp. 219-234.

Mulero, A. (2013): "Significado y tratamiento del paisaje en las políticas de protección de espacios naturales en España”, Boletín de la Asociación de Geógrafos Españoles, 62, pp. 129-145.

Murua, J. R., Astorkiza, I., Eguia, B. (2012): “Abandono e infrautilización del suelo agrario en la Cornisa Cantábrica. El caso del País Vasco", Revista Española de Estudios Agrosociales, 231, pp. 63-91.

Ormaetxea, O. (1998): La valoración de la calidad del paisaje vasco-cantábrico por la población. Métodos para su consideración objetiva, Leioa, Servicio Editorial de la Universidad del País Vasco, 302 pp.

Ormaetxea, O., De Lucio, J. V. (1992): "Valoración de la calidad del paisaje vasco por la población. Métodos para su consideración objetiva como criterio de conservación", Eusko Ikaskuntza-Cuadernos de sección: Historia, 20, pp. 491-504.

Pastor, A., Salaverri, B. (2012): Breve historia de Vizcaya y sus instituciones, Bilbao, Fundación Popular de Estudios Vascos, 318 pp.

Plan Forestal Vasco (1994-2030): Gobierno Vasco, Diputación Foral de Álava, Diputación Foral de Bizkaia y Diputación Foral de Gipuzkoa. http://www.nasdap.ejgv. 
euskadi.eus/contenidos/plan_programa_proyecto/plan_forestal/es_9394/adjuntos/ Plan_forestal.pdf (Fecha de consulta: 12/1/2016).

Plata, W., Gómez, M., Bosque, J. (2009): "Cambios de usos de suelo y expansión urbana en la Comunidad de Madrid (1990-2000)", Scripta Nova, XIII/293.

Porcal, M. C., Galdos, R., Ruíz, E. (2009): "Dinámica paisajística de las Áreas de Montaña del País Vasco a través de los cambios en la ocupación del suelo", en Pillet, F., Cañizares, M. C.; Ruíz, A. (coords.), Geografía, Territorio y Paisaje: el estado de la cuestión. XXI Congreso Nacional de Geógrafos Españoles, Ciudad-Real, Universidad de Castilla-La Mancha, pp. 123-153.

Real Sociedad Bascongada de Amigos del País (1786): Ensayo de la Sociedad Bascongada de los Amigos del País. Año 1766. Dedicado al Rey N. Señor. Vitoria: Thomas de Robles editor, pp. 181-182. Consultado en reedición (1985), Sociedad Guipuzcoana de Ediciones y Publicaciones.

Redacción El Diario Vasco (2016): Los vecinos de Ondarroa desalojados por un desprendimiento pasarán meses fuera de casa.

http://www.diariovasco.com/sociedad/201603/15/vecinos-ondarroa-desalojadosdesprendimiento-20160315134952.html (Fecha de consulta: 15/3/2016).

Rodríguez, F. (1979): "En torno al valor actual del paisaje en Geografía", Cuadernos geográficos de la Universidad de Granada, 9, pp. 23-42.

Ruíz, J. P. (dir.) (1993): Valoración del paisaje por el público y expertos en el País Vasco, Grupo de Ecología humana, paisaje y educación ambiental UAM, Vitoria-Gasteiz, Gobierno Vasco, Informe inédito 57 pp.

Ruíz, E., Galdos, R. (2008): Geografía del País Vasco, Donostia-San Sebastián, Nerea, $366 \mathrm{pp}$.

Ruíz, E., Galdos, R. (2013a): “Actividad agraria y paisaje. La ganadería, clave en la conservación del paisaje vasco-cantábrico", Boletín de la Asociación de Geógrafos Españoles, 63, pp. 379-398.

Ruíz, E., Galdos, R. (2013b): "La pérdida de los espacios agrarios y la artificialización del suelo y la forestación en España y en el País Vasco", Lurralde, 36, pp. 121-133.

Serrano, A., Martínez Del Olmo, W. (2004): "Estructuras diapíricas de la zona meridional de la Cuenca Vasco-Cantábrica”, en Vera, J. A. (ed.), Geología de España, pp. 334-338.

Serrano, D. (2007): "Paisaje y políticas públicas", Investigaciones Geográficas, 42, pp. 109-123.

Tagliaferro, C., Longo, A., Van Eetvelde, V., Antrop, M., Hutchinson, G (2013): "Landscape economic valuation by integrating landscape ecology into landscape economics", Environmental Science E Policy, 32, pp. 26-36.

Tarroja, A. (2008): "La dimensión social del paisaje", en Busquests, J., Cortina, J. (coords.), Gestión del paisaje. Manual de protección, gestión y ordenación del paisaje, Barcelona, Editorial Ariel Patrimonio, pp. 239-251.

UNESCO (1972): Convención sobre la protección del patrimonio mundial, cultural y natural. http://whc.unesco.org/archive/convention-es.pdf. (Fecha de consulta: 15/4/2016). 
Unamuno, M. (1952): De mi país, Madrid, Espasa-Calpe, Colección Austral 336, 146 pp.

Uriarte, R. (2008): “Administraciones públicas, iniciativa privada y repoblación forestal en el País Vasco cantábrico (1850-1936)", en González, L., Matés, J. M. (coords.), La modernización económica de los ayuntamientos: servicios públicos, finanzas y gobiernos municipales, Jaén, Universidad de Jaén, pp. 239-268.

Urzainki, M.A. (2007): De montes, parzonerías y parques naturales. Comunidades de montes en Gipuzkoa: Las Parzonerías, Donostia-San Sebastián, Universidad de Deusto, 343 pp.

Zube, E., Sell, J., Taylor, J. (1982): "Landscape perception: research, application and theory", Landscape Planning, 9, pp. 1-33.

Zubelzu, S., Allende, F. (2015): "El concepto de paisaje y sus elementos consituyentes: requisitos para la adecuada gestión del recurso y adaptación de los instrumentos legales en España". Cuadernos de Geografía/Revista Colombiana de Geografía, 24 (1), pp. 29-42

Fecha de recepción: 11 de noviembre de 2016.

Fecha de aceptación: 7 de noviembre de 2017. 